\title{
Prevalence of Microorganisms and Immunoglobulins in Children with Tonsillar Hypertrophy and Adenoiditis
}

\author{
Henrique Prestes Miramontes ${ }^{1}$ Djalma José Fagundes ${ }^{2}$ Julia Coelho Lima e Jurgielewicz ${ }^{3}$ \\ Haroldo Prestes Miramontes Neto ${ }^{4}$ Renan Gianotto de Oliveira ${ }^{3}$ Gustavo Gianotto de Oliveira ${ }^{3}$ \\ Maria Rosa Machado de Souza ${ }^{5}$
}

${ }^{1}$ MD; Extension Course Student, Universidade Anhembi Morumbi UAM, São Paulo, SP, Brazil

2 PhD; Universidade Federal de São Paulo - UNIFESP, São Paulo, SP, Brazil

${ }^{3}$ MS, Universidade Anhembi Morumbi - UAM, São Paulo, SP, Brazil

${ }^{4} \mathrm{MS}$, Universdidade Cidade de São Paulo - UNICID, São Paulo, SP, Brazil

5 PhD; Hospital Central de Guaianases, São Paulo, SP, Brazil;

Universidade Anhembi Morumbi - UAM, São Paulo, SP, Brazil
Address for correspondence Mr. Henrique Prestes Miramontes, Medical Sciences at the Universidade Anhembi Morumbi-UAM, Av. Prof. Olavo Avalone, 910, Colina das Estrelas, São Paulo, SP, Brazil (e-mail: henriquemiramontes@hotmail.com).

Int Arch Otorhinolaryngol 2014;18:311-315.

\begin{abstract}
Introduction: Benign idiopathic tonsillar hypertrophy ( $\mathrm{HBI}$ ) may affect a child's quality of life and sleep. Several studies have sought to relate the clinical features of HBI with the infectious and/or immunologic changes that occur.

Objective: To increase the knowledge of the etiology of HBI.

Data Synthesis: From 2012 to 2013 we conducted a retrospective observational study of 101 children with $\mathrm{HBI}$ who underwent tonsillectomies at Ambulatory ENT General Hospital of the East Zone of São Paulo City, a region with a poor socioeconomic population. Preoperative serologic results were available to confirm mononucleosis, cytomegalovirus, anti-streptolysin O (ASLO) and immunoglobulins. The mean patient age was 5.8 years ( $55 \%$ male, $45 \%$ female). Using the Mann-Whitney $U$ test, we identified significant gender differences in the parameters of immunoglobulins (Ig) M (IgM), IgA, and IgE. Forty-seven percent of the patients had increased ASLO levels, and 37\% had

Keywords

- child

- tonsillectomy

- immunoglobulins

- immune system

increased IgE levels.

Conclusion: An evaluation of a patient's serologic parameters and laboratory results may be relevant to the etiology and prevention of HBI. Based on the results obtained from the study sample, the identification of etiologic agents and causative factors remain a public health challenge that affects the quality of life of children.
\end{abstract}

\section{Introduction}

Beginning in the second trimester, tonsils form in the fetus at various locations. Their main function is to produce lymphocytes. ${ }^{1}$ Tonsils are named based on their location: the palatine tonsils (located between the glossopalatine and pharyngopalatine arches), the lingual tonsil (located at the posterior third of the tongue), the tubal tonsils (eustachian tubes), the pharyngeal tonsil, and the adenoid (adjacent to the choanae and the pharyngeal ostium of the eustachian tubes). All tonsillar lymph nodes form Waldeyer's ring, which represents 3 to $5 \%$ of the entire lymphatic system. ${ }^{2,3}$ Excessive infection caused by microorganisms or the allergic process can lead to hyperactivity of the tonsils and pharynx, which can increase its volume, thereby hindering the passage of air to the received

May 13, 2013

accepted

October 14, 2013

published online

May 15, 2014
DOI http://dx.doi.org/

10.1055/s-0033-1364174. ISSN 1809-9777.
Copyright $\odot 2014$ by Thieme Publicações License terms Ltda, Rio de Janeiro, Brazil 
choanae. ${ }^{4}$ The literature is controversial regarding the process of benign idiopathic tonsillar hypertrophy. Some authors relate this process to changes in the production of other immunoglobulins and to infections caused by nonspecific pathogens in the lymphoid tissue or mononucleosis, cytomegalovirus (CMV), and toxoplasmosis. Identifying the microbiota that colonize the tonsils has become increasingly important both for the connection with recurrent infections and the possible association with the hypertrophy of the tonsils and pharynx. . $^{5}$

Adenotonsillectomy may be necessary for patients with respiratory disorders caused by hypertrophy of the tonsils and adenoids; these patients show significant improvements in their oxygen saturation and quality of life after surgery. ${ }^{7,8}$ In view of this evidence, we aimed to evaluate the relationship between tonsillar hypertrophy, adenoids, microorganisms, and immunoglobulins in patients with surgical indications.

\section{Objectives}

The primary objective of the study was to identify the relationship between tonsillar hypertrophy and adenoids using serologic indicators (i.e., mononucleosis, toxoplasmosis, CMV, anti-streptolysin O [ASLO] and serum immunoglobulins [Ig] A [IgA], IgG, IgM, and IgE) in children between ages 1 and 10 years who underwent or were indicated for tonsillectomy.

Gender differences in the levels of immunoglobulins were also investigated.

\section{Materials and Methods}

This retrospective, observational study was performed from July 2012 to April 2013 by reviewing the medical records of children between the ages of 1 and 10 years who were indicated for adenotonsillectomy surgery at the ear, nose, and throat clinic at General Hospital of the East Zone of São Paulo City (a poor socioeconomic region).

\section{Inclusion and Exclusion Criteria}

The following inclusion criteria were applied. Children were enrolled if they complained of upper airway tract obstruction, difficulty swallowing, mouth breathing, snoring, sleep apnea, and recurrent tonsillar infections in the area where the surgical treatment was indicated. All children with the symptoms described above underwent an endoscopic nasopharynx examination and were included in the study if they showed tract obstruction of air $\geq 50 \%$ because of tonsillar hypertrophy. At that time, samples were collected for laboratory and serological tests. Patients with incomplete medical records were excluded from the study.

\section{Laboratory and Serology Tests}

According to the Ambulatory ENT General Hospital of the East Zone protocol, preoperative serology tests were requested for mononucleosis, toxoplasmosis, CMV, and serum immunoglobulins (i.e., ASLO, IgA, IgG, IgM, and IgE).
All tests were performed in a laboratory that was outsourced by the hospital. Nephelometry was used to examine the serum immunoglobulin levels (i.e., IgA, IgG, IgM, and IgE); serology was used for toxoplasmosis; chemiluminescence was used for CMV; and passive hemagglutination was used for mononucleosis serology. The ASLO test was used as the parameter for the streptolysin $\mathrm{O}$ dosage.

\section{Statistical Analysis}

Data were tabulated and analyzed using STATA version 12.1 (Stata Corp.,Texas, USA). The variables related to age and immunoglobulin levels were analyzed using the mean and standard deviation, and categorical variables were determined by absolute and relative frequencies (the Friedman test). The results were stratified by gender and compared using the Mann-Whitney $U$ test to determine significant differences, and $p$ values $<0.05$ were considered significant.

\section{Results}

\section{Description Sample}

This study evaluated 101 children between the ages of 1 and 10 years ( $55.4 \%$ male, $44.5 \%$ female) with tonsillar hypertrophy who were undergoing adenotonsillectomy. The mean age was $5.8( \pm 2.19)$ years. Of the participants, $<5 \%$ were between 1 and 3 years old and $45 \%$ were between 5 and 7 years old ( $\mathbf{- T a b l e ~} \mathbf{1}$ ).

\section{Serum Test Results}

According to the preoperative serologic tests, 90 and $43 \%$ of the children had never had contact with toxoplasmosis and CMV, respectively. However, $54 \%$ of the children had immunity to $\mathrm{CMV}$, indicating that at some point of their lives, they had contact with the agents. However, only $9 \%$ of the toxoplasmosis cases showed immunity, although none had acute illness. As shown in - Table 2, we did not observe acute toxoplasmosis infections, but two children (1.98\%) were seropositive for CMV.

Regarding mononucleosis, $13 \%$ of the children had reagents, meaning that they had contact with the EpsteinBarr virus (EBV) or had active infections by the agent. The immunoglobulin levels were compared with the reference values and are displayed by the relative frequencies (-Table 3). Immunoglobulins play an important role in detecting humoral immune response to infectious and allergic processes. Thus, we observed that $\sim 33 \%$ of the patients had increased IgG levels, 30\% had increased IgA levels, and

Table 1 Profiles of children undergoing adenotonsillectomy

\begin{tabular}{|l|l|l|}
\hline & $n$ & $\%$ \\
\hline Gender & & \\
\hline Male & 56 & 55.4 \\
\hline Female & 45 & 44.6 \\
\hline Age (mean \pm SD) & $5.82 \pm 2.19$ & Max: 10 and min: 1 \\
\hline
\end{tabular}

Abbreviation: SD, standard deviation. 
Table 2 Results of serologic tests for mononucleosis, IgG and IgM toxoplasmosis, and Cytomegalovirus

\begin{tabular}{|c|l|l|}
\hline \multirow{2}{*}{} & \multicolumn{2}{|c|}{ IgG } \\
\cline { 2 - 3 } & Reagent & Not Reagent \\
\hline IgM & & \\
\hline Toxoplasmosis, $n(\%)$ & & \\
\hline Reagent & $01(0.99)$ & $0(0)$ \\
\hline Not reagent & $09(8.91)$ & $91(90)$ \\
\hline Cytomegalovirus, $n(\%)$ & & \\
\hline Reagent & $02(1.98)$ & $02(1.98)$ \\
\hline Not reagent & $54(53.5)$ & $43(42.6)$ \\
\hline Mononucleosis, $n(\%)$ & $13(12.87)$ & $88(87.13)$ \\
\hline
\end{tabular}

Abbreviation: Ig, immunoglobulin.

$37 \%$ had increased IgE levels. The mean and standard deviation for these immunoglobulins were $1162 \pm 251,140 \pm 86$, and $253 \pm 186$, respectively. Regarding IgM, only $3.96 \%$ of the patients had increased values, which had little correlation with tonsillar hypertrophy.

All patients showed symptoms, including complaints of recurrent respiratory infections or signs of sleep apnea, and there was at least one obstruction of the nasal pharynx (50\%). Despite the increase in immunoglobulins that correlated with tonsillar hypertrophy, some patients did not show the same symptoms. When comparing the gender results, we found that the IgM values were significantly lower for boys. IgA and IgE values differed between genders also, which suggests a greater exposure to allergens in boys than girls (-Table 4).

ASLO is released by gram-positive bacteria that colonize the upper airway and is usually responsible for respiratory infections in children. Approximately $47 \%$ of the patients had increased ASLO levels.

\section{Discussion}

Tonsillectomy (with or without adenoidectomy) is the most common surgery among children. It is associated with improved quality of life and sleep, although its causes and its
Table 3 Reference values for the assayed immunoglobulins

\begin{tabular}{|c|l|}
\hline Reference values $(\mathrm{mg} / \mathrm{dL})$ & $n(\%)$ \\
\hline Serum dosage IgG & $01(0.99)$ \\
\hline$<420$ & $67(66.34)$ \\
\hline $420-1,240$ & $33(32.67)$ \\
\hline$>1,240$ & \\
\hline Serum dosage IgM & $01(0.99)$ \\
\hline$<50$ & $96(95.05)$ \\
\hline $50-300$ & $04(3.96)$ \\
\hline$>300$ & \\
\hline Serum dosage IgA & $04(3.96)$ \\
\hline$<18$ & $67(66.37)$ \\
\hline $18-160$ & $30(29.7)$ \\
\hline$>160$ & \\
\hline Serum dosage IgE & $0(0)$ \\
\hline 0.4 & $64(63.37)$ \\
\hline $0.4-352$ & $37(36.63)$ \\
\hline$>352$ & $54(53.47)$ \\
\hline Serum dosage ASLO & $46.53)$ \\
\hline$<250$ & \\
\hline$>250$ & \\
\hline
\end{tabular}

Abbreviation: ASLO, anti-streptolysin O; Ig, immunoglobulin.

effects on the immune system (e.g., reducing infections) are still controversial. ${ }^{9}$

As shown in this study, CMV and EBV agents have been cited in the literature as possible causes of tonsillar hypertrophy. Using polymerase chain reaction, a study in Turkey noted the presence of some types of herpesviruses, including CMV, mononucleosis, and EBV, in children 2 to 9 years of age and a reported positivity of 25.2 to $11.3 \%$ for EBV and CMV among children with adenoid hypertrophy and adenoiditis. ${ }^{10}$

Another study conducted in China by Zhang and colleagues demonstrated a correlation between EBV and adenoid hypertrophy; $51.9 \%$ of the children had EBV in tissues with adenoid and tonsillar hypertrophy, although it was absent in the

Table 4 Gender comparison of the immunoglobulin and ASLO levels

\begin{tabular}{|c|c|c|c|c|c|c|}
\hline & \multicolumn{2}{|c|}{ Male $(n=56)$} & \multicolumn{2}{|c|}{ Female $(n=45)$} & \multirow[t]{2}{*}{$95 \% \mathrm{Cl}$} & \multirow[t]{2}{*}{$p^{\mathrm{a}}$} \\
\hline & Mean & SD & Mean & SD & & \\
\hline $\lg M$ & 138.82 & 145.51 & 149.39 & 61.91 & $120-166$ & 0.0235 \\
\hline $\lg G$ & $1,161.34$ & 244.47 & $1,162.29$ & 263.33 & $1,112-1,211$ & 0.6445 \\
\hline $\lg A$ & 157.89 & 91.28 & 117.46 & 74.49 & $122-156$ & 0.0072 \\
\hline $\lg \mathrm{E}$ & 609.23 & 729.3 & 204.14 & 282.15 & $308-548$ & 0.0001 \\
\hline ASLO & 268.12 & 163.12 & 234.41 & 212.05 & $216-289$ & 0.1641 \\
\hline
\end{tabular}

Abbreviations: a, Wilcoxon Mann Whitney test; ASLO, anti-streptolysin O; Cl, confidence interval; Ig, immunoglobulin; SD, standard deviation. 
blood. This result aligns with our results, as our study only performed serology and did not investigate this agent in the tissue. ${ }^{11}$

Regarding the gender differences, Zhang et al found no statistical significance. These results differ from those in this study, which found that the values of $\operatorname{IgM}, \operatorname{IgA}$, and $\operatorname{IgG}$ differed between boys and girls. ${ }^{11}$ Other viral agents of epidemiologic importance were also cited in a cross-sectional study by Proença-Modena and colleagues, who reported high rates of common respiratory viruses $(97.5 \%$ of children with chronic adenotonsillar disease and no history of acute respiratory symptoms). ${ }^{12}$ Human adenovirus was found more frequently (47\%), followed by enterovirus (40\%), rhinovirus (38\%), bocavirus (30\%), metapneumovirus (17\%), and respiratory syncytial virus (16\%). ${ }^{12}$ Our study should have considered these viruses profiles; however, it has proven difficult to do so in daily practice.

Generally, in clinical practice, adenotonsillectomy reduces the incidences of respiratory infections and allergic obstruction. The adverse impact of immune adenotonsillectomy surgery in children has been studied for years, but past reports have shown different postoperative immunoglobulin levels in the long and short term. ${ }^{9}$

$\operatorname{IgG}$ is the main immunoglobulin found in blood, corresponding to $\sim 70$ to $75 \%$ of the total immunoglobulin level. An IgG deficiency in children may be related to repeated respiratory infections. ${ }^{13}$ In contrast, our findings suggest a $30 \%$ increase in IgG, which can be related to the organism response.
In their last publication of adenotonsillectomy, Santos and colleagues followed patients for 14 months over two visits. The first follow-up visit occurred 1 to 2 months postsurgery, and the second occurred 12 to 14 months postsurgery. The immunoglobulin results were compared using the Friedman test (three groups), and they showed the preoperative value of $\operatorname{IgG}(p=0.002)$ and the significant reduction of $\operatorname{IgA}$ $(p=0.026)^{9}$

-Fig. 1A shows that the IgM values are low with little variability; only one individual (age 6 years) had increased IgM values. We observed greater variability for IgG ( - Fig. 1B), with predominance among the benchmarks. Our findings, however, are similar to those found by Santos et al, ${ }^{9}$ who reported normal levels in the preoperative and postoperative periods (1 to 2 months). However, after 12 months of followup, the $\operatorname{IgA}$ and $\operatorname{IgG}$ levels showed significant increases. The level of IgA immunoglobulin improved in $30 \%$ of the samples; its primary biological function is to protect against invading organisms, such as viruses and bacteria on mucosal surfaces, and inhibiting their adhesion to epithelial cells. IgA does not fix complement; therefore, it can work against microorganisms without triggering the cascade of inflammation that damages the epithelial surfaces. However, it does not always protect against reinfection. It also promotes the decreased absorption of a variety of antigens or allergens (inhaled or ingested) that can trigger immune responses. ${ }^{14}$ Note that we used the serum IgA and not the dosage salivate - salivary IgA levels. In a second step, it should be studied.

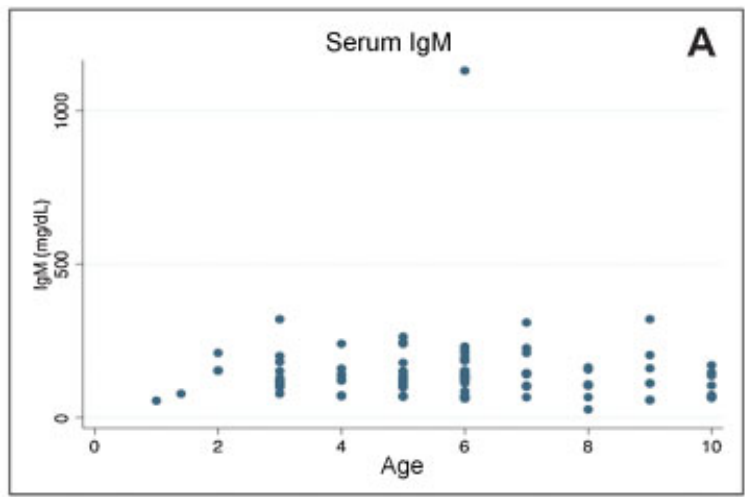

Graph 1. Scatter plot of serum IgM by age

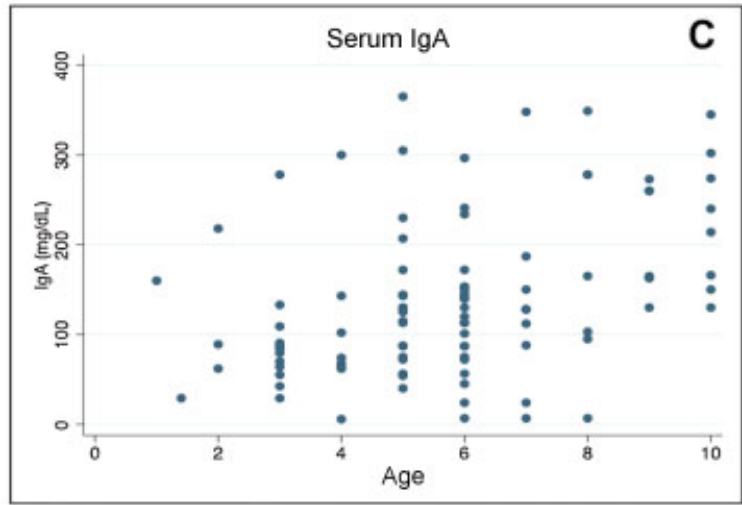

Graph 3. Scatter plot of serum IgA by age

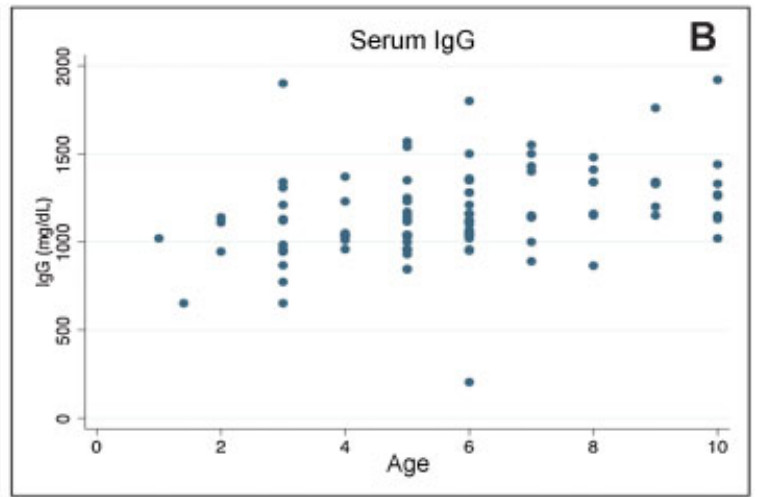

Graph 2. Scatter plot of serum IgG by age

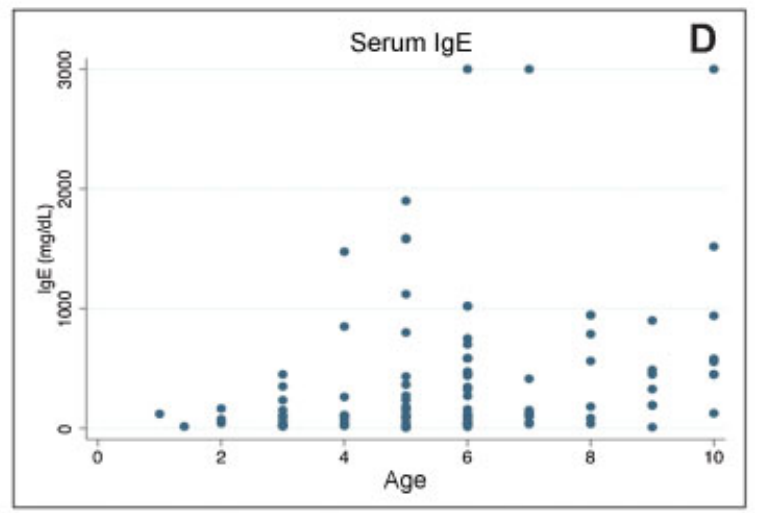

Graph 4. Scatter plot of serum lgE by age

Fig. 1 Scatter plot of serum immunoglobulin (Ig) M ( $\lg M ; A), \lg G(B), \lg A(C)$, and $\lg E(D)$ levels by age. 
Note that the IgA (- Fig. 1.C) levels remained within the parameters for all ages, and 30\% of the patients showed increases. IgE (-Fig. 1D) appears to increase with age and was increased by $37 \%$. Griffin et al have reported a $20 \%$ increase in $\operatorname{IgE}$ in children undergoing adenotonsillectomy, but they found no evidence of symptom improvement after surgery, and their follow-up period was only 1 year. ${ }^{15}$

The etiology of tonsillar hypertrophy, as many studies have suggested, is related to the presence of infectious agents, such as viruses and bacteria that are commonly found in the microflora of the upper airway and in the humoral immune response to the body's sensitivity to one or more allergens.

Identifying the main etiologic agents remains a public health challenge.

\section{Conclusion}

Based on our results, we found that there was no relationship between the positive serology for toxoplasmosis and tonsillar hypertrophy. However, we observed a positive relationship between the serology for CMV and tonsillar hypertrophy. Regarding mononucleosis, a low percentage (13\%) of patients had positive serology.

Regarding ASLO, there was a $47 \%$ increase in the patients studied. Concerning the dosages of serum immunoglobulins in these patients, there was an increase in the serum levels of immunoglobulins IgA, IgE, and IgG but not an increase or decrease in IgM.

\section{References}

1 Huang SW, Giannoni C. The risk of adenoid hypertrophy in children with allergic rhinitis. Ann Allergy Asthma Immunol 2001;87(4):350-355
2 Marchesan IQ. Fundamentos em Fonoaudiologia: aspectos clínicos da motricidade oral. Rio de Janeiro: Guanabara Koogan; 1998: 23-36

3 Gross CW, Harrison SE. Tonsils and adenoids Pediatrics. Review 2000;21(3):75-78

4 Dalley AF, Moore KL. Anatomia Orientada para Clínica. 4a edição. Rio de Janeiro: Guanabara Koogan; 2001 pp. 851-867

5 Brodsky L, Moore L, Stanievich J. The role of Haemophilus influen$z a e$ in the pathogenesis of tonsillar hypertrophy in children. Laryngoscope 1988;98(10):1055-1060

6 Kielmovitch IH, Keleti G, Bluestone CD, Wald ER, Gonzalez C. Microbiology of obstructive tonsillar hypertrophy and recurrent tonsillitis. Arch Otolaryngol Head Neck Surg 1989;115(6): 721-724

7 Arrarte JL, Lubianca Neto JF, Fischer GB. The effect of adenotonsillectomy on oxygen saturation in children with sleep disordered breathing. J Bras Pneumol 2007;33(1):62-68

8 Soccol BB, Rocha RT, Henrique VP, Marchi RD. Avaliação do impacto da adenotonsilectomia sobre a qualidade de vida em crianças com hipertrofia das tonsilas palatinas e faríngeas. Rev Bras Otorrinolaringol 2009;75(1):64-69

9 Santos FP, Weber R, Fortes BC, Pignatari SS. Short and long term impact of adenotonsillectomy on the immune system. Braz J Otorhinolaryngol 2013;79(1):28-34

10 Karlıdağ T, Bulut Y, Keleş E, et al. Presence of herpesviruses in adenoid tissues of children with adenoid hypertrophy and chronic adenoiditis. Kulak Burun Bogaz Ihtis Derg 2012;22(1):32-37

11 Zhang X, Li H, Liu X, et al. Study and analysis on the quantitative detection of EBV-DNA in adenoidal hypertrophic and tonsillitis tissues of children. J Clin Otorhinolaryngol 2009;23(24):1108-11

12 Proença-Modena JL, Pereira Valera FC, Jacob MG, et al. High rates of detection of respiratory viruses in tonsillar tissues from children with chronic adenotonsillar disease. PLoS ONE 2012;7(8):e42136

13 Burtis CA, Ashwood ER. Textbook of Clinical Chemistry. 3 ed. Philadelphia: Saunders; 1999

14 Rúpolo BS, Mira JGS, Kantor Junior O. Deficiência de IgA. J Pediatr (Rio J) 1998;74(6):433-440

15 Griffin JL, Ramadan HH, Adham RE. Prevalence of IgE-mediated hypersensitivity in children with adenotonsillar disease. Arch Otolaryngol Head Neck Surg 1994;120(2):150-153 